\title{
March 2014 Arizona Thoracic Society Notes
}

The March 2014 Arizona Thoracic Society meeting was a special meeting. In conjunction with the Valley Fever Center for Excellence and the Arizona Respiratory Center the Eighteenth Annual Farness Lecture was held in the Sonntag Pavilion at St. Joseph's Hospital at 6 PM on Friday, April 4, 2014. The guest speaker was Antonio "Tony" Catanzaro, MD from the University of California San Diego and current president of the Cocci Study Group. There were 57 in attendance representing the pulmonary, critical care, sleep, and infectious disease communities.

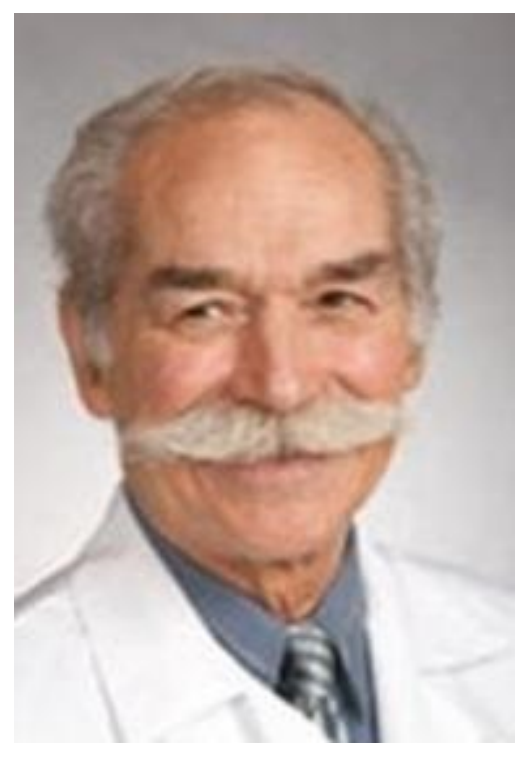

Dr. Antonio Catanzaro

After opening remarks by Arizona Thoracic Society president, Lewis Wesselius (a former fellow under Dr. Catanzaro at UCSD), John Galgiani, director of the Valley Fever Center for Excellence, gave a brief history of the Farness lecture before introducing Dr. Catanzaro. The lecture is named for Orin J. Farness, a Tucson physician, who was the first to report culture positive coccidioidomycosis (cocci or Valley Fever). The title of Dr. Catanzaro's talk was "Coccidioidomycosis, Why I Have Found It So Interesting". Dr. Catanzaro came to San Diego from Georgetown to study the immunology of sarcoidosis. Much to his surprise, he found little sarcoidosis in San Diego and was looking for a new direction. While attending the California Thoracic Society meeting, Tony met Dr. Hans Einstein from Bakersfield, California, the leading authority on Valley Fever. He persuaded Tony to attend the Cocci Study Group meeting, held in conjunction with the California Thoracic Society meeting. Dr. Catanzaro reviewed his investigations of Valley Fever including transfer factor, hypercalcemia associated with Valley Fever and treatment with ketoconoazole, fluconazole, itraconazole, and posaconazole (1-4). Prominently mentioned Hans Einstein from Bakersfield, 
John Galgiani from Tucson, Bernie Levine from Phoenix and J. Burr Ross also from Phoenix.

The Cocci Study Group meeting was held the following day, Saturday, April 5th at the University of Arizona College of Medicine, Phoenix. The next meeting of the Arizona Thoracic Society is on Wednesday, April 23, 2014, 6:30 PM at Shea Hospital.

Richard A. Robbins, M.D.

\section{References}

1. Catanzaro A, Einstein H, Levine B, Ross JB, Schillaci R, Fierer J, Friedman PJ. Ketoconazole for treatment of disseminated coccidioidomycosis. Ann Intern Med. 1982 Apr;96(4):436-40. [CrossRef] [PubMed]

2. Catanzaro A, Galgiani JN, Levine BE, Sharkey-Mathis PK, Fierer J, Stevens DA, Chapman SW, Cloud G. Fluconazole in the treatment of chronic pulmonary and nonmeningeal disseminated coccidioidomycosis. NIAID Mycoses Study Group. Am J Med. 1995;98(3):249-56. [CrossRef] [PubMed]

3. Galgiani JN, Catanzaro A, Cloud GA, Johnson RH, Williams PL, Mirels LF, Nassar F, Lutz JE, Stevens DA, Sharkey PK, Singh VR, Larsen RA, Delgado $\mathrm{KL}$, Flanigan $\mathrm{C}$, Rinaldi MG. Comparison of oral fluconazole and itraconazole for progressive, nonmeningeal coccidioidomycosis. A randomized, doubleblind trial. Mycoses Study Group. Ann Intern Med. 2000;133(9):676-86. [CrossRef] [PubMed]

4. Catanzaro A, Cloud GA, Stevens DA, Levine BE, Williams PL, Johnson RH, Rendon A, Mirels LF, Lutz JE, Holloway M, Galgiani JN. Safety, tolerance, and efficacy of posaconazole therapy in patients with nonmeningeal disseminated or chronic pulmonary coccidioidomycosis. Clin Infect Dis. 2007;45(5):562-8. [CrossRef] [PubMed] 